\title{
A Study on the Distances of Small Mobile Robot Moves towards Infants
}

\author{
Ami Yasaka ${ }^{1}$ and Akiko Watanabe ${ }^{2}$ \\ 1. Graduate School of Science and Technology for Future Life, Tokyo Denki University, Tokyo 120-8551, Japan \\ 2. Department of Architecture, Tokyo Denki University, Tokyo 120-8551, Japan
}

\begin{abstract}
In recent years, it is remarkable that various robots are being developed, and the development of robot technology is beginning to be taken into an actual living space. There are still many questions that we will have to answer for the harmonization of living together with a robot. This study is focused on "the study of how to plan and design a living space in harmonizing with robots", and focused on the effects of infants (subjects) along with the distance between robots and themselves. The study is to seek for the minimum distance for the subjects who felt that "I do not want a robot to be any closer being approached to me". This experiment was conducted among 30 infants at the kindergarten, utilizing a small experimental robot. A small robot whose dimension is $120 \mathrm{~mm}(W) \times 130 \mathrm{~mm}(D) \times 70 \mathrm{~mm}(H)$, approaching infants as is to see if it would make any differences to the infant's reactions.
\end{abstract}

Key words: Small mobile robot, individual distance, infants, living space.

\section{Introduction}

It is remarkable that various robots are being developed and the development of robot technology is beginning to be practically adopted into an actual living space, in last few years, coming out from their industry space. However, living together with a robot still has many challenges due to the fact that some robots are still being designed without considering the physiological harmonization and correlation among human beings, robots by themselves, and the architectural design space.

Although the study on human beings and robots has just started, there are very few researches which seek for the impacts and implications between robots and infants, in terms of the environmental physiological effects and the behavior which could only be generated by the human beings at their very younger age instead of fully matured adults.

Corresponding author: Ami Yasaka, graduate student, research field: architectural planning. E-mail: yasaka-ami@xsj.biglobe.ne.jp.

\subsection{Thesis-Related Research}

Robotics research in the field of architectural planning has been promoted by the "research space for the coexistence of humans and robots" [1-3], Waseda University. In addition, Nakazima and Sato [4, 5] study the distance of robot and human in "personal distance against mobile robot". In addition, the authors make a survey of the personal distance against robot for adults, in "study on planning technique of living space harmony with robots" [6-8] yet.

\subsection{Research Objectives}

This study is a part of the "study on planning techniques of living space in harmonizing with robots", especially to identify a "comfort zone" in (mm) focusing on the infants. We conducted the experiments, as stated in the previous "Abstract" and "Introduction" sections, a small robot approaching toward infants to investigate the physiological effects based on their reactions.

The experiment was also conducted with the robot approaching toward them in the different angles, and at 
the different speed, observing the infants reactions and discomfort.

Overall, the correlations among infants, the size of experimental space and robot with various speeds to approach infants were observed out of these experiments.

\section{Methods}

\subsection{Experiment Summary}

For the experiment, the research was conducted gathering 30 infants who are at the age of four and five years old (Table 1).

For the experimental environment, we chose a classroom at the kindergarten in Yokohama city, Kanagawa Japan and the subjects (target infants) were the kindergarten children who went to the same kindergarten making sure that they felt comfortable of the experimental space that they were used to stay at, eliminating the possibility of other discomfort factors.

The dimension of experimental space (class room of kindergarten) was $6.5 \mathrm{~m}$ by $6.0 \mathrm{~m}$ (Fig. 1). A small mobile robot was being used in this experiment. The external dimension of the robot was $120 \mathrm{~mm}(W) \times 130$ $\mathrm{mm}(D) \times 70 \mathrm{~mm}(H)$. The robot was battery operated and controlled by a wireless remote controller.

In the experiment, we conducted two postures of infants who sit on the floor and stand up on the floor, having a robot approaching toward them from $5 \mathrm{~m}$ distance to start with.

We conducted the experiment trying to have a robot approached toward them with five different angles $\left(0^{\circ}\right.$, $\left.45^{\circ}, 90^{\circ}, 135^{\circ}, 180^{\circ}\right)$ and two different speeds $(0.08$ $\mathrm{m} / \mathrm{s}$ and $0.24 \mathrm{~m} / \mathrm{s}$ ).

The questionnaires about the impressions are distributed, each infant was asked to answer the survey, before and after the experiment, using a method to select the most appropriate adjective phrase out of four adjective phrases on questionary survey.

In addition, we asked the subjects (infants) to draw the full scale picture of "the robot which they wanted to live together with" after the first experiment.

\subsection{Detailed Dimensions of a Small Mobile Robot}

The small mobile robot used in this experiment was equipped by two wheels for it to move around, and its external dimensions was $120 \mathrm{~mm}(W) \times 130 \mathrm{~mm}(D) \times$ $70 \mathrm{~mm}(H)$.

We set the experimental scenario that the robot could only move toward the infants at the two different speeds. The robot was remotely controlled from a distance of $5 \mathrm{~m}$ away from it. Fig. 2 shows the figure of the robot.

\subsection{Experimental Conditions}

In this experiment, the mobile robot approached toward infants who were posing as "standing on the floor" and "sitting on the floor".

It approached toward the infants from their right hand side in the five different angles form the distance of $5 \mathrm{~m}$ to start with, and the robot stopped when the infants felt "they do not want a robot to come any closer".

Distance was measured from the center of the shoe sole of the infants to the front of the mobile robot.

The infants were given the following instructions:

(1) We would measure the distance when they felt that they did not want the robot to come any closer;

Table 1 Average data.

\begin{tabular}{ll}
\hline Thirty infants & Data \\
\hline Average age & 4.6 years \\
Average height & $110.1 \mathrm{~cm}$ \\
Sitting height & $58.8 \mathrm{~cm}$ \\
\hline
\end{tabular}

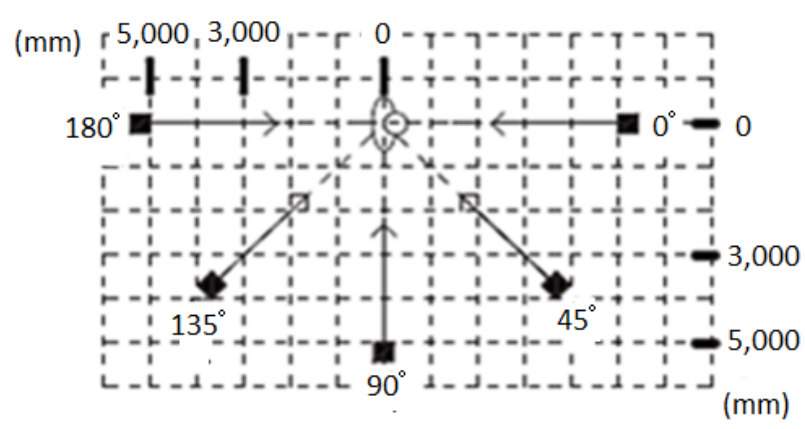

Fig. 1 Experiment place. 
Measurement:

$120 \mathrm{~mm}(W) \times 130 \mathrm{~mm}(D) \times 70 \mathrm{~mm}(H)$

Speed:

(1) $0.08 \mathrm{~m} / \mathrm{s}$

(2) $0.24 \mathrm{~m} / \mathrm{s}$

Fig. 2 Small mobile robot.

(2) We informed them that in the first experiment, the robot would approach toward them from five different directions, two different speeds, and they would pose two different postures. This would make in total of 20 different patterns of experiments;

(3) During measurement, we asked them to avoid changing the direction of their bodies, and asked them to face toward the robot, at all times.

\section{Results of Experiment}

After carrying out first experiment, even if the distance with the robot approached to $0 \mathrm{~m}$ to the infants, 18 out of 30 infants did not feel unpleasant in both "standing position" nor "sitting on the floor" postures.

After the experiment, there are notably two types of infant groups identified. A group of infants who felt uncomfortable unless a robot was away from them, and another group of infants who did not feel uncomfortable even a robot is $0 \mathrm{~m}$ away from them. In the following analysis, we will segregate these infants into two groups.

One did not feel unpleasant (18 out of 30), and the others felt unpleasant (12 out of 30 ).

\subsection{Standing Position}

\subsubsection{Measured Distance}

Table 2 shows the average of measured distance with related deviation to indicate the fact that overall variability exists due to the individual variations. Fig. 3 shows the average figures.

As shown in Table 2, the average measured distance at $0.08 \mathrm{~m} / \mathrm{s}$ was between $90.1-103.8 \mathrm{~cm}$; and at 0.24 $\mathrm{m} / \mathrm{s}$, it was between $69.6-108.9 \mathrm{~cm}$.

3.1.2 Tendency of Measured Distance for the Varieties of Angles and Two Different Speeds

In Fig. 3, there are no significant differences between the cases for the speed at $0.08 \mathrm{~m} / \mathrm{s}$ and at 0.24 $\mathrm{m} / \mathrm{s}$ with the angle changes from $0^{\circ}$ to $90^{\circ}$. However, the difference was observed when the robot approaches toward infants from their back at the angles of $135^{\circ}$ and $180^{\circ}$. The biggest difference was observed when the robot approached toward infants with $180^{\circ}$ angle which created the distance of $20.5 \mathrm{~cm}$ between the robot and infants, both at $0.08 \mathrm{~m} / \mathrm{s}$ and at $0.24 \mathrm{~m} / \mathrm{s}$.

\subsubsection{Multiple Comparison Correlation Analysis}

Multiple comparison correlation analysis was performed for three cases: $0.08 \mathrm{~m} / \mathrm{s}$ and angles, 0.24 $\mathrm{m} / \mathrm{s}$ and angles, and the speed of $0.08 \mathrm{~m} / \mathrm{s}$ and $0.24 \mathrm{~m} / \mathrm{s}$ to inspect the relations with the speed and the angles (Tables 3-5). The meaningful difference was not detected having $5 \%$ as the levels of significance. There was not the meaningful difference between the speed at $0.08 \mathrm{~m} / \mathrm{s}$ and $0.24 \mathrm{~m} / \mathrm{s}$.

It became clear that there were no levels of significance in terms of the angles, either.

Therefore, our concluded assumption out of this experience was that infants might feel discomfort when the distance is approximately $94.0 \mathrm{~cm}$ regardless of the speed and approached angles of a robot.

\subsection{Sitting on the Floor Posture}

\subsubsection{Measure Distance}

Table 6 shows the average of measured distance with

Table 2 Average of each personal space speed table in standing (unit: $\mathrm{cm}$ ).

\begin{tabular}{|c|c|c|c|c|c|}
\hline \multirow{2}{*}{ Speed } & \multicolumn{5}{|c|}{ Standard deviation } \\
\hline & $0^{\circ}$ & $45^{\circ}$ & $90^{\circ}$ & $135^{\circ}$ & $180^{\circ}$ \\
\hline $0.08 \mathrm{~m} / \mathrm{s}$ & 94.8 & 103.8 & 99.3 & 101.4 & 90.1 \\
\hline $0.24 \mathrm{~m} / \mathrm{s}$ & 108.9 & 98.1 & 98.3 & 86.0 & 69.6 \\
\hline Average & 104.0 & 106.4 & 104.9 & 99.0 & 84.1 \\
\hline Standard deviation & 55.9 & 68.9 & 82.1 & 84.7 & 80.3 \\
\hline
\end{tabular}




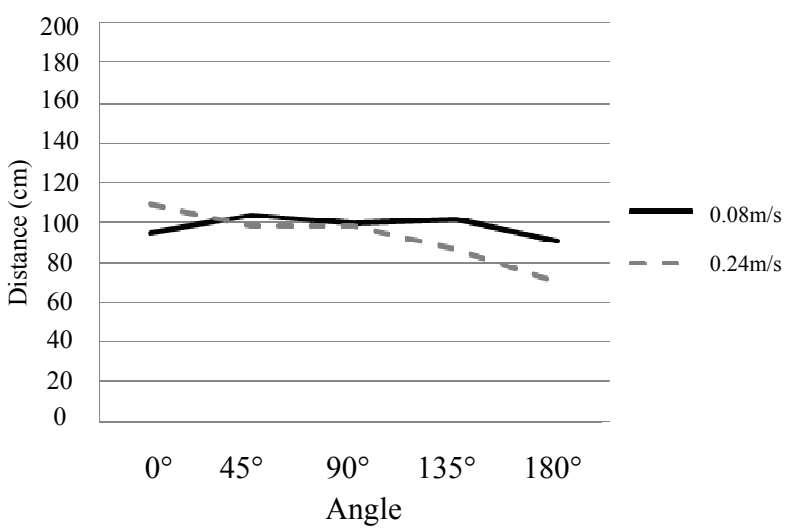

Fig. 3 Average graph of each personal speed at starting.

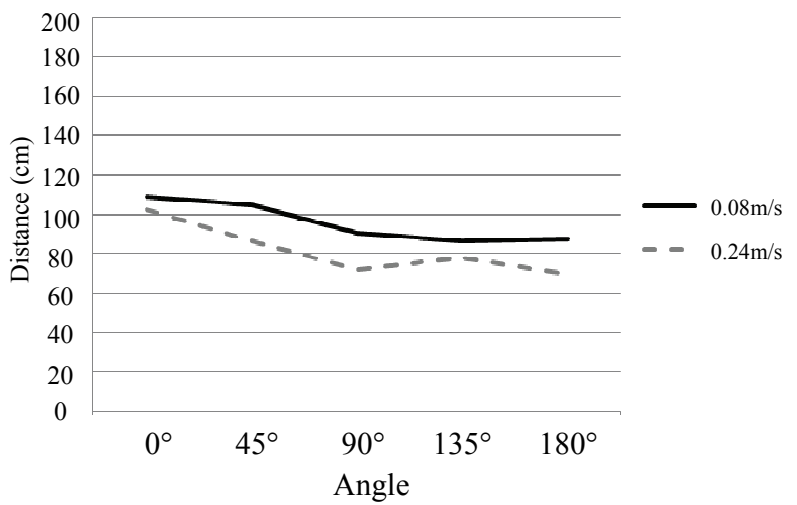

Fig. 4 Average graph of each personal speed at sitting on the floor.

Table 3 An analysis of variance list of the angle in speed $0.08 \mathrm{~m} / \mathrm{s}$ in the standing position.

\begin{tabular}{llllllll}
\hline Fluctuation factor & Sum of freedom & Degree of freedom & Mean square & $F$-ratio & $P$-ratio & $F(0.95)$ & $P(0.99)$ \\
\hline Total variation & $392,658.08$ & 59.00 & & & & & \\
Variation between subgroup & $1,436.40$ & 4.00 & 359.10 & 0.05 & 0.95 & 2.54 & 3.68 \\
Error variance & $391,221.68$ & 55.00 & $7,113.12$ & & & & \\
\hline
\end{tabular}

Table 4 An analysis of variance list of the angle in speed $0.24 \mathrm{~m} / \mathrm{s}$ in the standing position.

\begin{tabular}{|c|c|c|c|c|c|c|c|}
\hline Fluctuation factor & Sum of freedom & Degree of freedom & Mean square & $F$-ratio & $P$-ratio & $F(0.95)$ & $P(0.99)$ \\
\hline Total variation & $233,001.39$ & 59.00 & & & & & \\
\hline Variation between subgroup & $10,807.98$ & 4.00 & $2,701.99$ & 0.67 & 0.62 & 2.54 & 3.68 \\
\hline Error variance & $222,193.68$ & 55.00 & $4,039.88$ & & & & \\
\hline
\end{tabular}

Table 5 A $t$-test list of Welch of the speed in the standing position.

\begin{tabular}{lllll}
\hline Difference of the mean & Degree of freedom & $F$-ratio & $P$-ratio (both sides probability) & $P(0.975)$ \\
\hline 5.63 & 111.05 & 0.42 & 0.67 & 1.98 \\
\hline
\end{tabular}

related deviation to indicate the fact that overall variability exists due to the individual variations.

Fig. 4 shows the average figures.

As shown in Table 6, the average measured distance at $0.08 \mathrm{~m} / \mathrm{s}$ was between $86.7-109.2 \mathrm{~cm}$; and at 0.24 $\mathrm{m} / \mathrm{s}$, was between $69.8-102.8 \mathrm{~cm}$, respectively.

3.2.2 Tendency of Angles and Speed for the Infants Sitting Down on the Floor

The biggest difference was observed in the approach angles of $45^{\circ}$ and $90^{\circ}$ when a robot approached toward infants both at the speed of $0.08 \mathrm{~m} / \mathrm{s}$ and at the speed of $0.24 \mathrm{~m} / \mathrm{s}$. The deviation of the distance between infants and a robot in the approach angles of $45^{\circ}$ and $90^{\circ}$ was $18.8 \mathrm{~cm}$.

\subsubsection{Multiple Comparison Correlation Analysis}

Multiple comparison correlation analysis was also performed with three cases, namely at the speed of 0.08 $\mathrm{m} / \mathrm{s}$ and different angles, at the speed of $0.24 \mathrm{~m} / \mathrm{s}$ and different angles, and at the speed of $0.08 \mathrm{~m} / \mathrm{s}$ and 0.24 $\mathrm{m} / \mathrm{s}$ to inspect the correlations between the speed and the angles (Tables 7-9). The meaningful difference was not detected having $5 \%$ as the levels of significance. There was not the meaningful difference between speed at $0.08 \mathrm{~m} / \mathrm{s}$ and $0.24 \mathrm{~m} / \mathrm{s}$.

It became clear that there were no levels of significance in terms of the angles, either.

Table 6 Average of each personal space speed table in sitting on the floor (unit: $\mathrm{cm}$ ).

\begin{tabular}{lrrlrl}
\hline \multirow{2}{*}{ Speed } & \multicolumn{5}{c}{ Standard deviation } \\
\cline { 2 - 6 } & \multicolumn{1}{c}{$0^{\circ}$} & \multicolumn{1}{c}{$45^{\circ}$} & $90^{\circ}$ & $135^{\circ}$ & $180^{\circ}$ \\
\hline $0.08 \mathrm{~m} / \mathrm{s}$ & 109.2 & 104.9 & 90.8 & 86.7 & 87.6 \\
$0.24 \mathrm{~m} / \mathrm{s}$ & 102.8 & 86.2 & 72.0 & 77.9 & 69.8 \\
Average & 108.5 & 99.5 & 85.04 & 85.5 & 83.2 \\
Standard deviation & 68.1 & 68.9 & 60.8 & 68.9 & 90.2 \\
\hline
\end{tabular}


Table 7 An analysis of variance list of the angle in speed $0.08 \mathrm{~m} / \mathrm{s}$ in sitting on the floor.

\begin{tabular}{lcclllll}
\hline Fluctuation factor & Sum of freedom & Degree of freedom & Mean square & $F$-ratio & $P$-ratio & $F(0.95)$ & $P(0.99)$ \\
\hline Total variation & $352,297.39$ & 59.00 & & & & & \\
Variation between subgroup & $5,251.23$ & 4.00 & $1,312.81$ & 0.21 & 0.93 & 2.54 & 3.68 \\
Error variance & $347,046.16$ & 55.00 & $6,309.93$ & & & & \\
\hline
\end{tabular}

Table 8 An analysis of variance list of the angle in speed $0.24 \mathrm{~m} / \mathrm{s}$ in sitting on the floor.

\begin{tabular}{lcllllll}
\hline Fluctuation factor & Sum of freedom & Degree of freedom & Mean square & $F$-ratio & $P$-ratio & $F(0.95)$ & $P(0.99)$ \\
\hline Total variation & $218,584.60$ & 59.00 & & & & & \\
Variation between subgroup & $8,572.61$ & 4.00 & $2,143.15$ & 0.56 & 0.69 & 2.54 & 3.68 \\
Error variance & $210,011.99$ & 55.00 & $3,818.40$ & & & & \\
\hline
\end{tabular}

Table 9 A $t$-test list of Welch of the speed in sitting on the floor.

\begin{tabular}{lllll}
\hline Difference of the mean & Degree of freedom & $F$-ratio & $P$-ratio (both sides probability) & $P(0.975)$ \\
\hline 14.08 & 118.00 & 1.11 & 0.27 & 1.98 \\
\hline
\end{tabular}

Therefore, our concluded assumption out of this experience was that infants might feel discomfort when the distance is approximately $88.8 \mathrm{~cm}$ regardless of the speed and approached angles of a robot.

\section{The Full Scale Picture of "the Robot} Which Infants Wanted to Live Together with"

We asked the participants (infants) to draw the full scale picture of "a robot which they wanted to live together with" after the first experiment. Fig. 5 shows the example of the pictures.

\subsection{Grouping by the Picture Size}

The average height of the robot that infants drew was $28.2 \mathrm{~cm}$, along with the width of $20.7 \mathrm{~cm}$ in average.

Based on the graph shown in Fig. 6, since the correlation factor was 0.54 , we could easily conclude that there is a strong correlation between that height and width of the robot that the infants drew. The higher height they drew, the more width it becomes. On the contrary, the lower height they drew, the less width it becomes.

\subsection{Groupings by the Theme of Pictures}

After reviewing the pictures that infants drew, there were many pictures of robots based on the theme of "animal types (four legged robots)" and "transportation types" (Fig. 7).

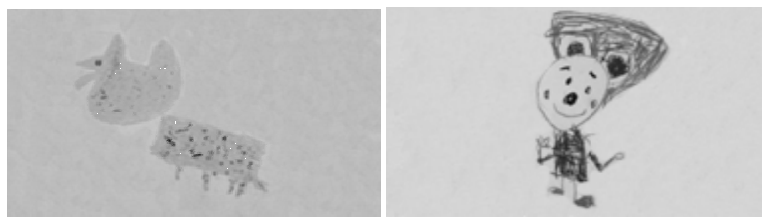

Fig. 5 The example of the pictures by infants.

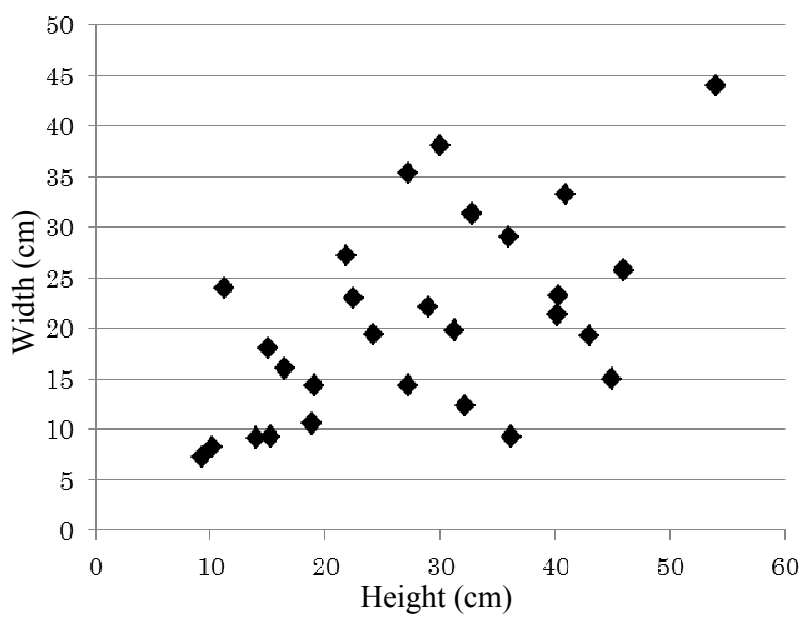

Fig. 6 The high painting of the infant and distribution map of "the width".

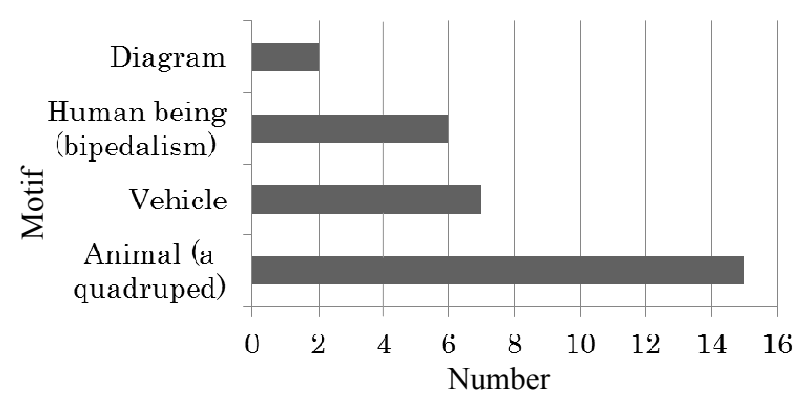

Fig. 7 Classification by the motif of the picture of the infant. 
We assume most of the reasons of infants drawing rabbits was that they wanted to feel that robots to a closer and loveable existence such as animals.

Therefore, they wanted to believe that they are willing to live together with robots in their actual lives, recognizing that the robots are their close existence.

\section{Consideration}

\subsection{Relations of Individual Physical Distance, Speed} and the Approached Angle

Based on the analysis of sections (3.1.3 Multiple Comparison Correlation Analysis and 3.2.3 Multiple Comparison Correlation Analysis), we concluded that the distance between the robot and the infants has no relations in terms of the speed and approached angles.

However, looking at Fig. 4, for the standing on the floor posture of infants, there is a distinct difference for the distance at the speed of $0.08 \mathrm{~m} / \mathrm{s}$ compared to the speed of $0.23 \mathrm{~m} / \mathrm{s}$ between the approached angles of $135^{\circ}$ and $180^{\circ}$.

Looking at Fig. 8, there are also the difference for the distance when the infants took "sitting on the floor posture" compared to the "standing up on the floor posture", at the speed of $0.08 \mathrm{~m} / \mathrm{s}$ versus $0.24 \mathrm{~m} / \mathrm{s}$ in any approached angles.

We assumed the reason being that when the infants looked at the robot in the lower angle, they felt and sensed that the distance between the robot and the infants were closer than it actually was.
We also observed the fact that the data in all graphs rises diagonally upward to the right.

We also identified that since infants have "personal space" in the direction of what they can see and visualize from their front zone, they took the physical distance between the robot and themselves longer, compared to the zone which was their behind where they could not see.

\subsection{Distance with the Robot Approached to $0 \mathrm{~m}$ to the Infants}

After conducting the experiment, we found out that more than half of participated infants did not fell discomfort even the robot approached them in $0 \mathrm{~m}$ for their "standing up on the floor" or "sitting down on the floor" postures.

For the infants allowed the robot to get close to even $0 \mathrm{~m}$ to them, many had a good impression on the robot, compared to the infants who did take the individual physical distance.

When we asked them the reason why they allowed the robot to get very close, many replied saying "they wanted to play with the robot".

We also assumed that the reason why they did not take any individual physical distance from the robot was due to the fact that they recognized the robot as a toy for them to play with compared to the adults, the "personal space" for infants has not been fully developed yet.

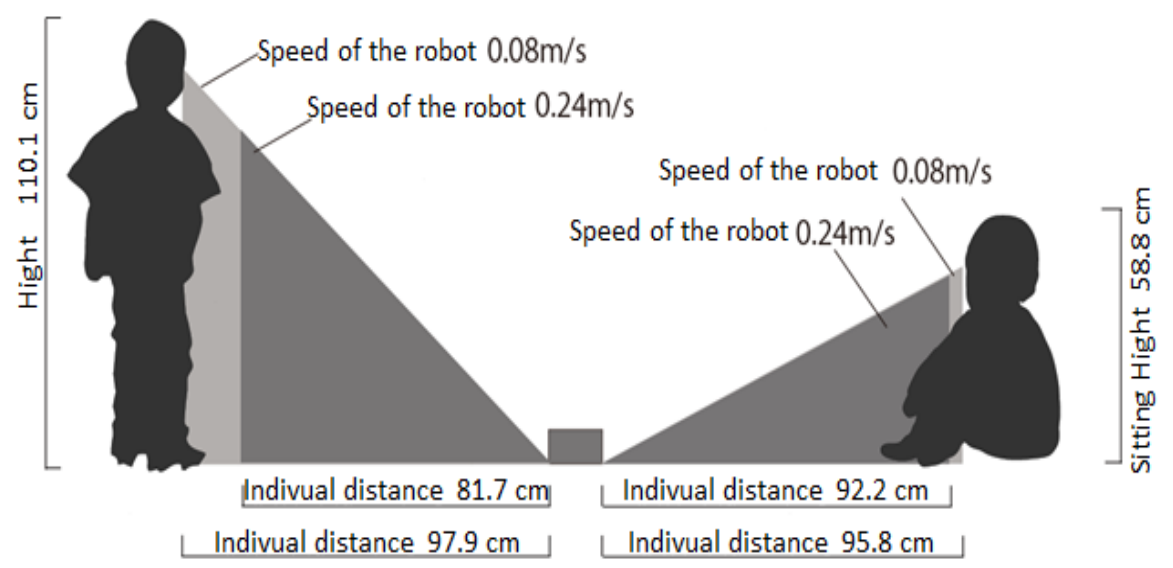

Fig. 8 Average distance of standing and sitting on the floor for the speed. 
Reviewing the research conducted by Burgess [9], "personal space" is fully established till the age of 12 years old as adults do. Therefore, many infants in our experiment did not feel discomfort due to the fact that their personal space is still in the development stage.

\section{Conclusions}

After our experiment and research, we find out the following in terms of the individual physical distance, utilizing the small mobile robot with the variations of $0.08 \mathrm{~m} / \mathrm{s}$ and $0.24 \mathrm{~m} / \mathrm{s}$ speeds attached to it with the infant's posturing "standing on the floor" and "sitting on the floor".

Infants tend to take their individual physical distance in the front zone.

There is no correlations and dependencies for the speed and approached angles of the robot toward the infants, in terms of the individual physical distance. However, there is a slight distinctions when the infants pose "standing up on the floor" posture and "sitting down on the floor" posture for the individual physical distance.

Infants have a tendency to prefer the small cute robot with the size of approximately $30 \mathrm{~cm}$ in height and 20 $\mathrm{cm}$ in width, based on the pictures they drew.

The objective of the experiment was to quantitatively measure and identify "the infant comfortable zone", experimenting a robot approaching to the infants in the different speed and angle.

The experimental result shows that infants tend to feel more uncomfortable and prohibit a robot to be closer when it approaches them from the straight angle, rather than a robot approaching from the back, and sideways.

There was no correlation affecting their comfort zone, regardless of the speed, angles, and infant posture, although there is a slight deviations.

However, infants tend to feel more comfortable and prefer the small cute robots when it comes to their comfort zone.

\section{References}

[1] A. Enta, H. Watanabe, T. Sano, K. Hayashida, A study of avoidable distance against robot, Journal of Architecture, Planning and Environmental Engineering 601 (2006) 81-85.

[2] K. Hayashida, A. Enta, Y. Yoshioka, M. Takahashi, Y. Sano, H. Watanabe, Comfortable distance between the man and the autonomy robot, Journal of Architecture, Planning and Environmental Engineering 651 (2010) 1133-1140

[3] Y. Yousuke, M. Thakahashi, H. Watanabe, A. Enta, Y. Sano, K. Hayashida, Characteristic behavior in follow-walking to leading robots, Journal of Architecture, Planning and Environmental Engineering 75 (652) (2010) 1399-1406.

[4] K. Nakazima, H. Sato, Personal distance against mobile robot, Journal of Japan Ergonomics Research Society 35 (2) (1999) 87-95.

[5] K. Nakazima, H. Sato, Personal distance against mobile robot: Part 2-Older persons, Journal of Japan Ergonomics Research Society 35 (4) (1999) 253-258.

[6] M. Aoki, A. Watanabe, A study on the distances of an upright/char-sitting small mobile robot to male adult individuals, Journal of Architecture, Planning and Environmental Engineering 664 (2011) 1093-1100.

[7] M. Aoki, A. Watanabe, A study on the distances of an upright/individual distance of a small robot moving towards adult male and female, Journal of Architecture, Planning and Environmental Engineering 66 (2013) 585-590.

[8] M. Sakai, A. Watanabe, A study on the distances of an upright/personal space small mobile robot moves towards standing or sitting elderly individuals, Journal of Architecture, Planning and Environmental Engineering 68 (2013) 827-832.

[9] J.W. Burgess, Development of social spacing in normal and mentally retarded children, Journal of Nonverbal Behavior 6 (1981) 89-95. 